\title{
Effect of apple and rosehip pomaces on colour, total phenolics and antioxi- dant activity of corn extruded snacks
}

\author{
Wioletta Drożdż, Ewa Tomaszewska-Ciosk, Ewa Zdybel, Hanna Boruczkowska, \\ Tomasz Boruczkowski, Piotr Regiec
}

Faculty of Food Science and Technology, Wroclaw University of Environmental and Life Sciences, Poland, *Corresponding author: e-mail: wioletta.drozdz@wnoz.up.wroc.pl

\begin{abstract}
Extrusion cooking technology was applied for obtaining corn extrudates fortified with various level (10-20\%) of rosehip pomace powder or apple pomace powder. The total polyphenols content, antioxidant activities (ABTS), organoleptic properties and colour of the extrudates were determined.

Pomace addition increased the level of total polyphenols content and antioxidant activity in obtained corn - pomace extrudates, especially in samples enriched with rosehip pomace. Extrudates with $20 \%$ of rosehip pomace addition characterized the highest polyphenols content and antioxidant activity. Only the slight decrease of some quality features - shape and size, taste and flavour, structure and colour of obtained extrudates was observed. Sample with fruit pomace addition showed increasing consistency evaluation. The extruded products by utilising fruit by-products got good evaluation of panelists and can be an excellent source of bioactive compounds in the daily human diet.
\end{abstract}

Keywords: apple pomace, rosehip pomace, extrusion, polyphenols, antioxidant activity.

\section{INTRODUCTION}

The food industry produces a large amount of by-products, generating a lot of problems associated with their utilisation. Most of these products are composted or consumed as animal feed. In recent years, more and more attention is paid to the possibility of food waste as raw materials to produce new products, ${ }^{\mathbf{1 , 2}}$. The main reason for searching for alternative treatment directions of these wastes is to minimize their impact on the environment and use of valuable compounds remaining in the by-products, such as vitamins, fiber or polyphenols ${ }^{3}$.

The main by-product of fruit industry in Poland is apple pomace, obtained by crushing and pressing apples during the clear juice process recovery. It represents approximately $30 \%$ of the original fruits. ${ }^{4}$. Apple pomace is a rich source of polyphenolic compounds belonging to the group of natural antioxidants ${ }^{5}$ and dietary fiber as well ${ }^{6}$. Polyphenols play the complex role in the human body include responsiblity for stimulating the growth of immunity, preventig tooth decay, and having beneficial effects in hypertension and hypercholesterolemia. Many studies also indicate that polyphenolic compounds inhibit the process of carcinogenesis at various stages of formation and development of cancer ${ }^{7}$. Therefore there has been an increase in the apple pomace utilization as a component of new functional foods ${ }^{8}$. Wang \& Thomas $^{9}$ and Carson at $\mathrm{al}^{\mathbf{1 0}}$ worked out a technology for preparation of bakery products with apple pomace addition. Sensory evaluation demonstrated that the experimental products were the same or more desirable than the products received by traditional recipe.

Another way to utilized apple pomace may want to use of these by-products as additives to a crunchy snack products. Due to the high popularity of the extruded snack products, the introduction to the recipe supplements containing high amounts of fiber, vitamins and polyphenols, can significantly improve the health status of the population.

The aim of this study was to obtain nutritionally improved corn extruded snacks with apple and rosehip pomaces as ingredients and their effect on some physico-chemical and sensory properties of the product.

\section{EXPERIMENTAL}

\section{Fruit pomace and corn snacks preparation}

The materials to be studied included corn grits, apple pomace and rosehip pomace. Commercial edible corn grits (moisture content 13 14\%) were purchased from a company Sante A. Kowalski Warszawa (Poland). Dried apple pomace with a moisture content of $8 \%$ was supplied by the Fruit Processing Plant of "Agropol" Potycz (Poland); dried rosehip pomace with a moisture content of $7 \%$ came from the fruit processed at the laboratory of the Department of Fruit, Vegetables and Cereals Technology, Wrocław University of Environmental and Life Sciences (Poland). The pomaces were ground in a universal knife grinder Pulverisette 19 Fritsch to obtain $1 \mathrm{~mm}$ particle size. Extruded products were manufactured from different ingredient combinations, corn grits only, and corn with different pomace at a low level 5\% and a maximum level 20\% (Tab.1). The samples were fixed in tightly-closed foil bags and conditioned at a temperature of $25^{\circ} \mathrm{C}$ for 24 hours. Immediately before the extrusion process the samples were re-stirred.

Table 1. Ingredients of the products

\begin{tabular}{|c|c|c|}
\hline Sample & & Contens \\
\hline Corn & & $100 \%$ corn grits \\
\hline \multirow{3}{*}{$\begin{array}{l}\text { Corn + rosehip } \\
\text { pomace }\end{array}$} & $10 \%$ & $\begin{array}{l}90 \% \text { corn grits }+10 \% \text { rosehip } \\
\text { pomace }\end{array}$ \\
\hline & $15 \%$ & $\begin{array}{l}85 \% \text { corn grits }+15 \% \text { rosehip } \\
\text { pomace }\end{array}$ \\
\hline & $20 \%$ & $\begin{array}{l}80 \% \text { corn grits }+20 \% \text { rosehip } \\
\text { pomace }\end{array}$ \\
\hline \multirow{3}{*}{$\begin{array}{l}\text { Corn + apple } \\
\text { pomace }\end{array}$} & $10 \%$ & $\begin{array}{l}90 \% \text { corn grits }+10 \% \text { apple } \\
\text { pomace }\end{array}$ \\
\hline & $15 \%$ & $\begin{array}{l}85 \% \text { corn grits }+15 \% \text { apple } \\
\text { pomace }\end{array}$ \\
\hline & $20 \%$ & $\begin{array}{l}80 \% \text { corn grits }+20 \% \text { apple } \\
\text { pomace }\end{array}$ \\
\hline
\end{tabular}


The process of extrusion was conducted in a single-screw extruder type 20Dn by Brabender, with a compression ratio of $4: 1$ and a round nozzle $4 \mathrm{~mm}$ in diameter. The single screw was rotating at $180 \mathrm{rpm}$ and the feeder at $50 \mathrm{rpm}$. The process of extrusion was carried out in temperature of $130^{\circ} \mathrm{C}$ for the first zone, $150^{\circ} \mathrm{C}$ for the second zone and $180^{\circ} \mathrm{C}$ for the third zone. The produced extrudates were kept in an air dryer at a temperature of $25^{\circ} \mathrm{C}$ for 48 hours.

\section{Extractions of raw ingredients and extrudates}

Two grams samples were extracted with $80 \%$ methanol (100 $\mathrm{mL}$ ) by shaking for $24 \mathrm{~h}$ at room temperature. Then the samples were placed in an ultrasonic water bath for 5 minutes at $4^{\circ} \mathrm{C}$. After being filtered through Schott filter papers, the extracts were used for the examination.

\section{Analysis of polyphenols}

Total phenols content in the obtained extracts were estimated by a colorimetric assay based on procedures described by Singleton and Rossi (1965) ${ }^{\mathbf{1 1}}$. Total polyphenols was determined by the Folin-Ciocalteu reagent by using gallic acid (GA) as a standard for the calibration curve. Results were read after $1 \mathrm{~h}$ at $765 \mathrm{~nm}$ in a spectrophotometer (Shimadzu UV-2401 PC). All determinations were performed in triplicate. The results of the assay were calculated and expressed as milligrams of gallic acid equivalent (GAE) per gram of dry weight (DW).

\section{Antioxidant activity}

The against ABTS radical was scavenging activity done according to the method of Re et al. ${ }^{12}$. The ABTS solution was diluted with redistilled water to reach absorbance of $0.700(0.02)$ at $743 \mathrm{~nm}$. After the addition of $60 \mathrm{~mL}$ of supernatant to $3 \mathrm{~mL}$ of diluted ABTS solution, the absorbance was read exactly $6 \mathrm{~min}$ after initial mixing in a spectrophotometer (Shimadzu UV-2401 PC). The antioxidant activities ABTS, were expressed as Trolox equivalent antioxidant capacity (TEAC) by using the calibration curve plotted against different amounts of Trolox. TEAC values were calculated and are expressed as Trolox equivalents (TE) per 100 grams of dry weight (DW).

The total polyphenols contents and ABTS scavenging effects were examined for apple pomace, rosehip pomace, corn grits and milled extrudates. All measurements were performed in triplicate

\section{Organoleptic properties}

Sensory profiles were recorded for the obtaining extrudates using protocol for organoleptic evaluation of extruded products ${ }^{\mathbf{1 3}}$. Attributes evaluated were shape and size (uniformity, smoothness, degree of expansion and color), consistency (crispness, hardness, brittleness, fragility), structure (porosity, appearance of the fracture and degree of crushing of extrudates when breaking), taste and smell (intensity of perceived taste and smell of a typical corn snacks) All attributes were determined using structured scale with a possible range of scores from 1 to 5 where the higher number (5) denoted better attributes of the product and the lowest number (1) the worst. A 10-member panel was recruited for sensory evaluation of obtained products; the panelists had previous experience in extruded snack evaluation. The panel comprised of workers of Faculty of Food Science, Wroclaw University of Environmental and Life Sciences, in a wide range of age (25-45 years).

\section{Measurement of colour assessment}

Colour was assayed spectrophotometrically using a Minolta CR-200 spectrophotometer in extrudates comminuted to particle size of $400 \mu \mathrm{m}$. Samples were placed in a glass cuvette, and color values from the three readings were averaged to give representative $\mathrm{L}^{*}$ $a^{*} b^{*}$ colour spaces, where $L^{*}$ indicates lightness, $a^{*}$ is the redness and $b^{*}$ is the yellowness. The hue angle $(\mathrm{H})$

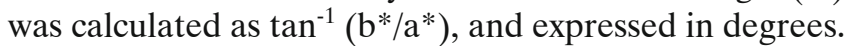
Chroma (C) was calculated as $\left(a^{* 2}+b^{* 2}\right)^{0,5}$

Results received were subjected to a statistical analysis using Statistica v. 9.0 software. One-way and two-way analysis of variance was carried out at a confidence level of $\mathrm{p} \leq 0.05$.

\section{RESULTS AND DISCUSSION}

By-products from the fruit and vegetable industry in the form of rosehip and apple pomace were used as an additive in extruded snack products in order to improve their nutritional characteristics

The total polyphenols content in raw corn grits - major ingredient in extruded snack products, was $2.87 \mathrm{mg}$ gallic acid/g. The total polyphenols value of fruit pomace used to produce extruded snack was considerable higher than unextruded corn. The greatest total polyphenols value was exhibited for rosehip pomace (29.20 mg gallic $\mathrm{acid} / \mathrm{g})$. It was observed a lower polyphenol content in apple pomace (6.49 $\mathrm{mg}$ gallic acid/g) compared to rosehip pomace, however it was twice more than in corn grits. Comparing with previous results on apple pomace ${ }^{\mathbf{1 4}, 15}$ the total polyphenols content in our research was very similar.

Both of the detected fruit pomace had higher antioxidation activity than raw corn grits $(29,9 \mu \mathrm{M}$ Trolox/100g). The ABTS scavenging effects were $6020 \mu \mathrm{M}$ Trolox $/ 100 \mathrm{~g}$ and $141,15 \mu \mathrm{M}$ Trolox/100 $\mathrm{g}$ for rosehip pomace and apple pomace respectively.

The results of total polyphenols value and antioxidant activity for extrudates were shown in Fig. 1. In this stu$\mathrm{dy}$, it is demonstrated that the addition of fruit pomace in extrudates caused positive influence on polyphenols value and antioxidant activity in corn - rosehip pomace extrudates and corn - apple pomace extrudates and it depended on fruit pomace addition level and fruit pomace varieties.

The polyphenols value and antioxidant activity of control sample were $2.62 \mathrm{mg}$ galic acid/g and $28.5 \mu \mathrm{M}$ Trolox $/ 100 \mathrm{~g}$ respectively. After extrusion the results were slightly lower compared to unextruded corn grits. This was agreeable to the finding by Stojceska et al. ${ }^{\mathbf{1 6}}$ and Chiu et al. ${ }^{17}$. The studies have shown that extrusion processing caused no negative influences on the ABTS scavenging abilities or even improved antioxidant activity of corn extrudates.

The polyphenols content of corn - apple pomace extrudates was in the range from 3.28 to $4.61 \mathrm{mg}$ galic $\mathrm{acid} / \mathrm{g}$. These values differ significantly from the sample 

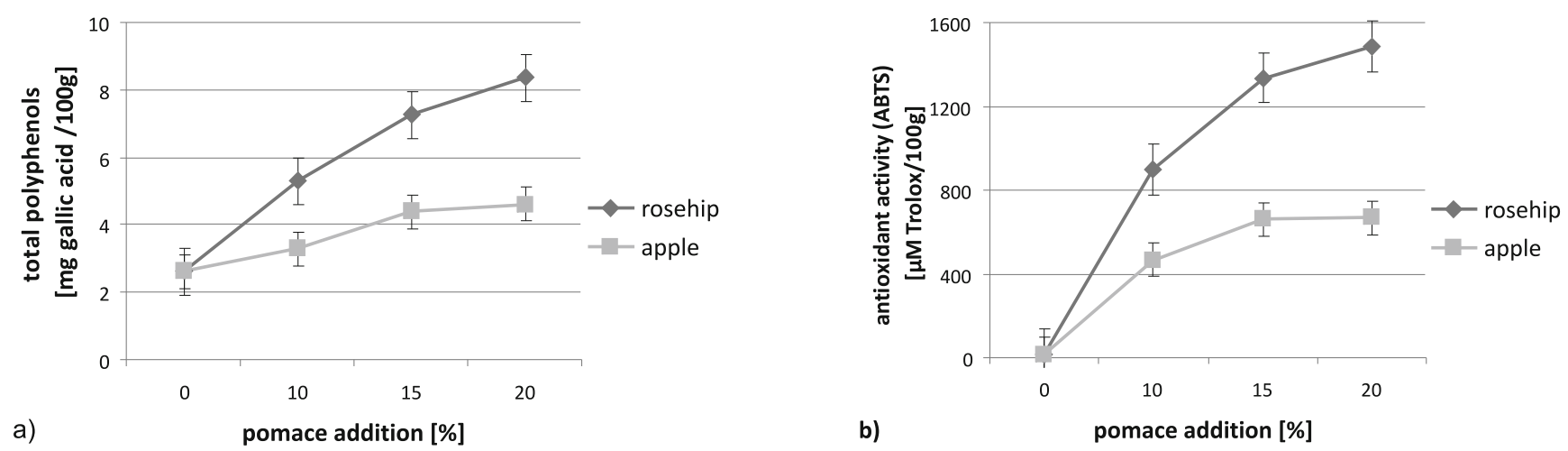

Figure 1. Total polyphenols content a) and antioxidant activity b) of extrudates
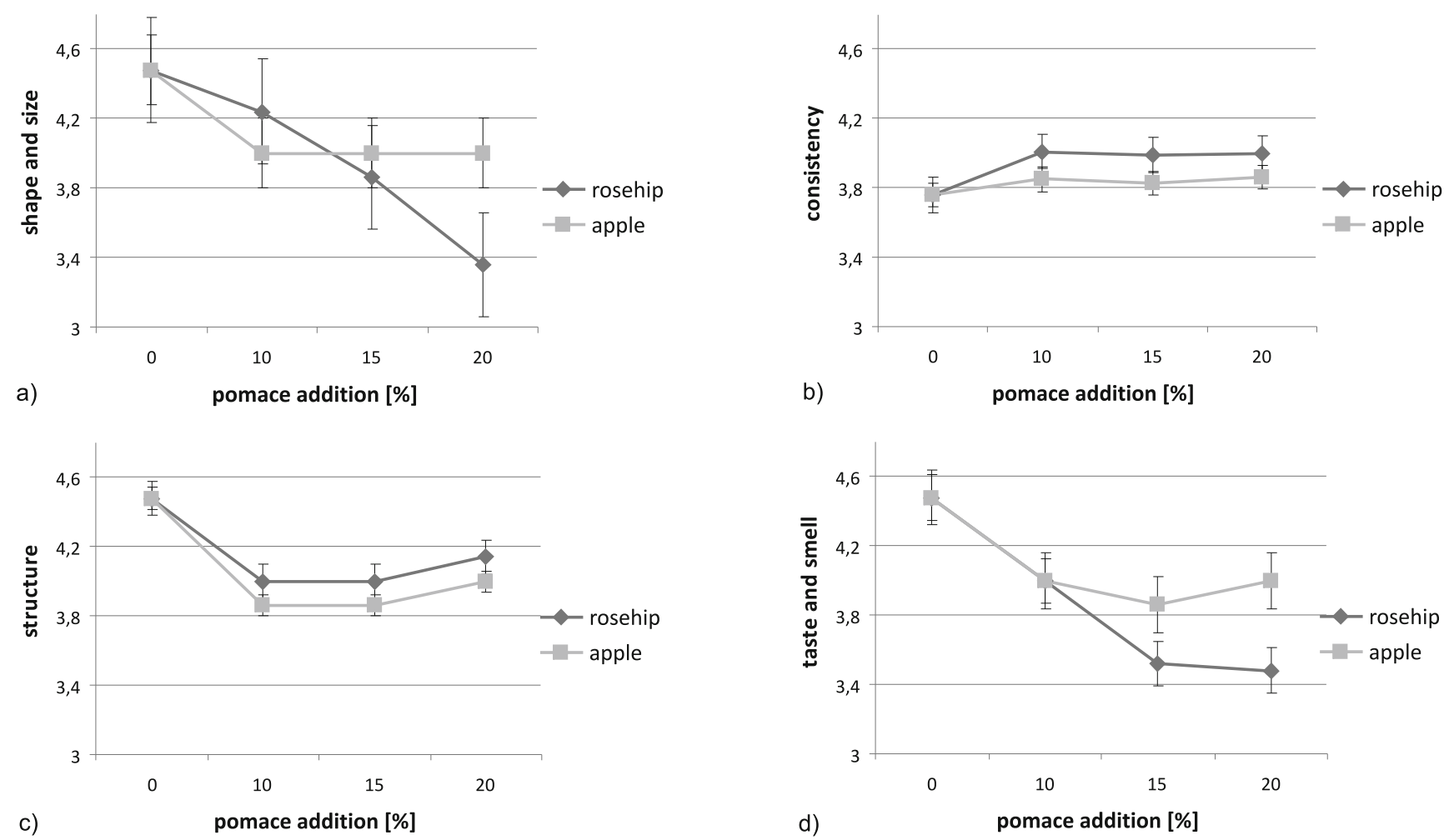

Figure 2. Organoleptic assessment of extrudates a) shape and size, b) consistency, c) structure, d) taste and smell

without pomace. With higher apple pomace addition, there was an increase in total polyphenols value but the samples with $15 \%$ and $20 \%$ of pomace did not differ statistically. Antioxidant activity of these extrudates increased from 46,77 to $76.92 \mu \mathrm{M}$ Trolox/100g and were significantly different in each formulation

Extrudates produced with rosehip pomace showed a range of total polyphenols between 5.3 and $8.35 \mathrm{mg}$ galic acid/g, and antioxidant activity between 660.7 and $1486.9 \mu \mathrm{M}$ Trolox/100g. The results were very high and were significantly higher compared to corn extrudates without pomace and from extrudates with apple pomace. Samples with $15 \%$ and $20 \%$ of rosehip pomace did not differ signifiacantly in polyphenols content and antioxidant activity. According to the previous studies ${ }^{18,19,20}$, the rosehip pomace is a rich source of antioxidants, therefore even a small amount of this material in snacks caused a significant increase in antioxidant activity in a final product. Already a small addition $(10 \%)$ of fruit pomace lead to the significant increase of polyphenols and antioxidants content in the sample.

Corn is a very common major ingredient in extruded cereal and snack products but the polyphenols and antioxidants value is very low. The result revealed that corn crisps after enrichment of the rosehip or apple pomace could be an excellent source of polyphenols and antioxidants. Similar results were reported by another authors where extrudates were enriched with other ingredients (e.g., soy protein and beans) for higher nutritional functionality 21,22 .

The food product offered to the consumer should not only have a high content of nutrients, but also should characterized by sensory attractiveness.

Organoleptic evaluation is one of the most important indicators of the product quality. Meeting the requirements of both the appearance, texture, consistency, taste and possible high proportion of pomace is not an easy task.

The results of organoleptic properties of produced snacks were shown in Fig. 2. The addition of fruit pomace to extrudates resulted in progressively lower evaluation of some attributes.

However, the level of the apple pomace addition was shown to have not a significant effect on most of the sensory attributes. Organoleptic evaluation of these extrudates was about 4. Panelists rated them as the product of a smooth surface with small corrugations, fairly steadily 
expanded, crisp and crumbly texture and slightly uneven porosity, pleasant slightly delicate aroma and typical flavor. Shape and size, as well as taste and flavour decreased significantly with rosehip pomace addition. These products have an uneven surface and were less expanded and characterized by taste and flavour worse than extrudates with apple pomace addition. Perhaps the use of suitable flavoring could have a positive impact on improving the attractiveness of extruded products with added rosehip pomace.

However, it could be observed that examined sample showed increasing consistency evaluation caused by the fruit pomace addition, which is possibly due to the organic acid content in fruit pomace, particularly rosehip pomace. Rosehip fruits are the richest natural source of ascorbic acid among all cultivated and wild trees and shrubs. The content of the acid in the fruit of rosehip is in the range $600-1000 \mathrm{mg}$ per $100 \mathrm{~g}$, and a large amount of this component remains in the pomace ${ }^{23}$. Some researches ${ }^{24,} 25$ have found that the addition of organic acid to extrudates caused a positive effect on properties that affect the product.

The colour was measured colorimetrically and expressed in the Hunter scale. Analysis of variance indicated that the effect of apple and rosehip pomace content on extrudate colour was significant (Table 2). Pomace content significantly affected the colour $\mathrm{L}^{*}, \mathrm{a}^{*}$ and $\mathrm{b}^{*}$ of extrudates in each formulation. The increase pomace content in samples led to the decrease in lightness of obtained extrudates to the level of 50.88 in the rosehip pomace and 52.08 in the case of apple pomace. The redness of the products also varied significantly in all extrudates. Increasing pomace content resulted with the higher redness especially in samples with rosehip pomace. Samples containing pomace showed lower value of $b^{*}$ than samples without pomace. The increase in rosehip pomace content led to the decrease in yellowness of product but the yellowness of the products with apple pomace did not vary statistical significantly.

The hue angle of extrudastes with apple pomace ranged from 80.48 to 86.31 as compared to the control sample which was 86.86. As pure yellow has a hue angle of 90 , this reflects that the products have a yellowish colour. In comparison, extrudates with rosehip pomace values ranging from 77.04 to 79.40 . This indicates a change more toward red. It is evident that with the increasing rosehip pomace level product became more reddish. This is due to the color of rosehip, the plant which contain anthocyanins-compounds affecting red colour of rosehip. The chroma represents the intensity or degree of the colour saturation. Chroma values for the products with pomace addition ranged from 21.77 to 28.62 (on a scale of $0-100)$, as compared to the control sample, which had

Table 2. The results of extrudates colour $\left(L^{*}, a^{*}, b^{*}\right)$

\begin{tabular}{|l|r|r|r|r|}
\hline \multicolumn{2}{|l|}{ Samples } & $\mathrm{L}^{*}$ & \multicolumn{1}{c|}{$\mathrm{a}^{*}$} & $\mathrm{~b}^{*}$ \\
\hline Corn & $10 \%$ & 64.43 & -4.21 & 38.39 \\
\hline \multirow{3}{*}{ Corn + rosehip pomace } & $15 \%$ & 56.54 & 3.96 & 24.46 \\
\cline { 2 - 5 } & $20 \%$ & 53.95 & 6.17 & 25.56 \\
\hline \multirow{3}{*}{ Corn + apple pomace } & $10 \%$ & 55.64 & 1.90 & 21.88 \\
\cline { 2 - 5 } & $15 \%$ & 52.43 & 2.93 & 21.62 \\
\cline { 2 - 5 } & $20 \%$ & 52.09 & 3.97 & 21.53 \\
\hline LSD & & 1.61 & 0.12 & 0.68 \\
\hline
\end{tabular}

significantly higher chroma value 38.74 . Furthermore, it can be seen that the product with apple pomace had less colour saturation (had a lower chroma value) compared to the product with rosehip pomace.

\section{CONCLUSION}

The polyphenols content and antioxidant activities of obtained extrudates were higher for corn - pomace samples than for raw corn extrudates, although the properties were dependent on the pomace varietes and its addition level. Corn-rosehip pomace snacks characterized higher polyphenols content and antioxidant activity than corn-apple pomace snacks.

Despite the slight decrease of some quality features (shape and size, structure, taste and flavour) extrudates with $20 \%$ of rosehip pomace addition can be considered as the best due to the highest polyphenols content and antioxidant activity. Organoleptic properties of corn-pomace extrudates were on score level about of 3.5-4, which means that panellists evaluated the product as good. Snacks produced with the rosehip or apple pomace may be a new type of functional food because of its high content of polyphenols and antioxidants, which have a beneficial effect on the human body.

\section{LITERATURE CITED}

1. Nawirska, A. \& Kwaśniewska, M. (2005). Dietary fibre fractions from fruit and vegetable processing waste. Food Chem. 91, 221-225. DOI:10.1016/j.foodchem.2003.10.005.

2. Osawa, K., Chinen, C., Takanami, S., Kuribayashi, T. \& Kurokouchi, K. (1995). Studies on effective utilisation of carrot pomace. II. Effective utilisation to cake, dressings and pickles. Research Report of the Nagano State Laboratory of Food Technology, 23, 15-18.

3. Laufenberg, G., Kunz, B. \& Nystroem, M. (2013) Transformation of vegetable waste into value added products: (A) the upgrading concept; (B) practical implementations, Bioresource Technology. 87, 167-198.

4. Grigoras, C.G., Destandau, E., Fougère, L. \& Elfakir, C. (2013). Evaluation of apple pomace extracts as a source of bioactive compounds. Industrial Crops and Products 49, 794-804, doi.org/10.1016/j.indcrop.2013.06.026.

5. Bai, X., Zhang, H. \& Ren, S. (2013). Antioxidant activity and HPLC analysis of polyphenol-enriched extracts from industrial apple pomace. J Sci Food Agric, 93, 2502-2506, DOI 10.1002/jsfa.6066.

6. Yan, H. \& Kerr, W.L. 2013. Total phenolics content, anthocyanins, and dietary fiber content of apple pomace powders produced by vacuum-beld drying. J. Sci. Food Agric. 93, 1499-1504, DOI 10.1002/jsfa.5925.

7. Czapski, J. (1999). The use of fruit and vegetables in the functional foods production. Żywność, Nauka, Technologia, Jakość, 4, 91-101 (in Polish).

8. Shalini, R. \& Gupta, D.K. (2010). Utilization of pomace from apple processing industries: a review. J. Food Sci. Technol. 47 (4), 365-371, DOI: 10.1007/s13197-010-0061-x

9. Wang, H.J. \& Thomas, R.L. (1989). Direct use of apple pomace in bakery products. J. Food Sci., 54 (3), 618-620. DOI: 10.1111/j.1365-2621.1989.tb04665.x.

10. Carlson, K.J., Collins, J.L. \& Penfield, M.P. (1994). Unrefined, dried apple pomace as a potential food ingredient. J. Food Sci. 59 (6), 1213-1215. DOI: 10.1111/j.1365-2621.1994. tb14679.x.

11. Singleton, V.L., Rossi Jr., J.A., (1965). Colorimetric of total phenolics with phosphomolybdic-phosphotungstic acid reagents. Am. J. Enol. Viticult. 16, 144-158. 
12. Re, R., Pellegrini, N., Proteggente, A., Pannala, A., Yang, M., Rice-Evans, C. (1999). Antioxidant activity applying an improved ABST radical cation decolorization assay. Free Radical Biol. Med., 26, 1231-1237.

13. Sensory analysis - Methodology, PN-ISO 6658.

14. García, Y.D., Suárez, B.V. \& Picinelli Lobo, A. (2009). Phenolic and antioxidant composition of by-products from the cider industry: Apple pomace. Food Chem. 117 731-738, doi:10.1016/j.foodchem.2009.04.049.

15. Suárez, B., Álvarez, Á.L., García, Y.D., del Barrio, G., Picinelli Lobo, A. \& Parra, F. (2010) Phenolic profiles, antioxidant activity and in vitro antiviral properties of apple pomace. Food Chem. 120 339-342, doi: 10.1016/j.foodchem.2009.09.073.

16. Stojceska, V., Ainsworth, P., Plunkett, A. \& Ibanoglu, S. (2009) The effect of extrusion cooking using different water feed rates on the quality of ready-to-eat snacks made from food by-products Food Chem. 114 226-232, doi:10.1016/j. foodchem.2008.09.043.

17. Chiu, H.W., Peng, J.C., Tsai, S.J. \& Lui, W.B. (2012) Effect of Extrusion Processing on Antioxidant Activities of Corn Extrudates Fortified with Various Chinese Yams (Dioscorea sp.) Food Bioprocess Technol 5, 2462-2473, DOI 10.1007/ s11947-011-0675-7.

18. Ercisli, S. (2007). Chemical composition of fruits in some rose (Rosa spp.) species. Food Chem. 104, 1379-1384. DOI:10.1016/j.foodchem.2007.01.053.

19. Su, L., Yin, J.J., Charles, D., Zhou, K., Moore, J. \& Yu, L. (2007) Total phenolic contents, chelating capacities, and radical-scavenging properties of black peppercorn, nutmeg, rosehip, cinnamon and oregano leaf. Food Chem. 100, 990-997. doi:10.1016/j.foodchem.2005.10.058.

20. Olsson, M.E., \& Gustavsson, K.E. (2004). Inhibition of cancer cell proliferation in vitro by fruit and berry extracts and correlations with antioxidant levels. J. Agricul. Food Chem. 52, 7264-7271.

21. Anton, A.A., Fulcher, R.G., \& Arntfield, S.D. (2009). Physical and nutritional impact of fortification of corn starch-based extruded snacks with common bean (Phaseolus vulgaris L.) flour: Effects of bean addition and extrusion cooking. Food Chem. 113, 989-996. doi:10.1016/j.foodchem.2008.08.050.

22. Yu, L., Ramaswamy, H.S., \& Boye J. (2009). Twin-screw extrusion of corn flour and soy protein isolate (SPI) blends: A response surface analysis. Food Bioprocess. Technol. DOI:10.1007/s11947-009-0294-8.

23. Nawirska, A. (2001). Chemical composition of chokeberry, pear, apple and rosehip pomace and evaluation of heavy metals removal on fruit pomace. Zeszyty Naukowe Akademii Rolniczej we Wrocławiu, 407, 55-71 (in Polish).

24. Chabrat, E., Abdillahi, H., Rouilly, A. \& Rigal, L. (2012). Influence of citric acid and water on thermoplastic wheat flour/ poly(lactic acid) blends. I: Thermal, mechanical and morphological properties. Industrial Crops and Products 37, 238- 246. DOI:10.1016/j.indcrop.2011.11.034.

25. Obuchowski, W. \& Michniewicz, J. (1993). Extrusion. Possible effects on the product quality. Przeglad Zbożowo Młynarski, 11, 5-7 (in Polish). 